\title{
Low cognitive ability in early adulthood is associated with reduced lung function in middle age: the Vietnam Experience Study
}

\author{
Douglas Carroll, ${ }^{1} \mathrm{G}$ David Batty, ${ }^{2,3}$ Laust H Mortensen, ${ }^{4}$ lan J Deary, ${ }^{3}$ \\ Anna C Phillips ${ }^{1}$
}

${ }^{1}$ School of Sport and Exercise Sciences, University of Birmingham, Birmingham, England

${ }^{2}$ Department of Epidemiology and Public Health, University

College London, London, England

${ }^{3}$ Centre for Cognitive Ageing and Cognitive Epidemiology, University of Edinburgh,

Edinburgh, UK

${ }^{4}$ Department of Social Medicine, University of Copenhagen,

Copenhagen, Denmark

\section{Correspondence to}

Professor Douglas Carroll, School of Sport and Exercise Sciences, University of Birmingham, Birmingham B15 2TT, England; carrolld@bham.ac.uk

Received 1 March 2011 Accepted 2 June 2011 Published Online First 27 June 2011

\begin{abstract}
Objective Reduced lung function has been linked to poorer cognitive ability later in life. In the present study, the authors examined the converse: whether there was a prospective association between cognitive ability in early adulthood and lung function in middle age. Methods Participants were 4256 male Vietnam-era US veterans. Cognitive ability was assessed by the Army General Technical Test on enlistment when participants were, on average, 20 years old (range: 17-34). Data on ethnicity and place of service were extracted from army files. Smoking behaviour, alcohol consumption, basic socio-demographics and whether participants had a physician-diagnosed chronic disease were determined by telephonic interview in middle age in 1985. Forced expiratory volume in one second $\left(\mathrm{FEV}_{1}\right)$ was measured by spirometry at a 3-day medical examination in 1986 . Height and weight were also measured.
\end{abstract}

Results In linear regression models, poor cognitive ability in early adulthood was associated with reduced lung function in middle age, first adjusting for age and height, $\beta=0.17, p<0.001$, then additionally adjusting for circumstantial, socio-demographic, lifestyle and health factors, $\beta=0.12, p=0.001$. The same results were obtained when the analysis was confined to nonsmokers.

Conclusion Not only is lung function related to subsequent cognitive ability, but poor cognitive ability earlier in life is also associated with reduced lung function in middle age.

\section{INTRODUCTION}

Low cognitive ability, assessed in childhood, adolescence or early adulthood, has been associated with a range of subsequent adverse health outcomes. A recent systematic review of nine cohort studies from various countries has indicated that the research was uniform in showing an inverse association between early life cognitive ability and increased all-cause mortality risk. ${ }^{1}$ More recently, a study of over one million Swedish men compared cognitive ability at military service conscription and mortality in middle age and found that low cognitive ability was associated with a greater risk of prematurely dying from all causes and was also related to the risk of death from specific causes, such as coronary heart disease, suicide and accidents. ${ }^{2}$ In addition, low cognitive ability in youth is associated with a range of clinical and behavioural risk factors of premature mortality, such as obesity, ${ }^{3} 4$ hypertension, ${ }^{4-6}$ markers of

\section{Key messages}

What is the key question?

- Is low cognitive ability in early adulthood related to poor lung function in middle age?

What is the bottom line?

- Low cognitive ability in early adulthood is associated with reduced lung function, as indicated by lower $\mathrm{FEV}_{1}, 18$ years later.

\section{Why read on?}

- Not only does lung function affect later cognitive ability, but poor cognition would appear to affect lung function later in life.

inflammation, ${ }^{78}$ cigarette smoking, ${ }^{4} 59$ excessive alcohol consumption ${ }^{10}$ and psychiatric illness. ${ }^{11} 12$

Poor lung function, typically indexed by low forced expiratory volume $\left(\mathrm{FEV}_{1}\right)$, has also been shown to predict all-cause, cause-specific mortality and a range of adverse health outcomes, ${ }^{13-15}$ even in non-smokers. ${ }^{16} 17$ A number of studies have now examined the association between lung function and cognitive ability; all studies have found that relatively poor lung function is associated with relatively low cognitive ability. However, the majority of studies to date have been crosssectional ${ }^{18-20}$ or, if longitudinal, have focused on the association between lung function and future cognitive ability and cognitive decline. ${ }^{21-25}$ Only two studies, as far as we are aware, have additionally examined the relationship between cognitive ability in youth and later lung function. In the British 1946 birth cohort, cognitive ability was measured in adolescence and $\mathrm{FEV}_{1}$ in middle age in 1778 study members; low cognitive ability was related to poorer subsequent lung function. ${ }^{24}$ In the other study, cognitive ability was assessed at age 11 years, as part of the Scottish Mental Survey 1932, and $\mathrm{FEV}_{1}$ was measured 68 years later in 460 participants; again, low cognitive ability was related to poorer subsequent lung function. ${ }^{25}$

Given the paucity of previous research, we examined the association between cognitive ability in youth and subsequent lung function in a substantially larger cohort of over 4000 US male Vietnam-era veterans. Cognitive ability data from early adulthood, that is, on army enlistment, were available and $\mathrm{FEV}_{1}$ was measured at a subsequent medical examination 18 years later when the men 
were middle aged. The two previous studies adjusted for only a few of the many potentially confounding variables. Due to the richness of the current data set, we were able to correct for a range of circumstantial, socio-demographic, behavioural and health-related covariates.

\section{METHODS}

Sample

Participants were Vietnam-era male military veterans. The effective sample size was 4256. Ethical approval for the study was given by various bodies, including the US Centers for Disease Control, and participants gave informed consent. Details of sampling at each stage of data collection are described more fully elsewhere. ${ }^{26} 27$ Inclusion criteria were: entered military service between 1 January 1965 and 31 December 1971, served only one term of enlistment and at least 16 weeks of active duty, earned a military specialty other than 'trainee' or 'duty soldier' and had a military pay grade at discharge no higher than sergeant.

\section{Data collection}

Information on place of service (Vietnam, other overseas, USA only), ethnicity (white, black, other) and cognitive ability was extracted from the military archives. On induction, that is, during early adulthood, participants completed the Army General Technical Test, ${ }^{28}$ which consists of verbal and arithmetic reasoning items and generates an IQ score. ${ }^{29}$ The Army General Technical test has been validated against components of the Wechsler Adult Intelligence Scale and found to show good correspondence. $^{30}$ The mean age when IQ was assessed was 20.4 years (range: 17.0-33.8). From a telephonic survey in 1985, socioeconomic position was measured using household income in midlife ( $\leq \$ 20000, \$ 20000-\$ 40000$ and $>\$ 40000$ ) and the grade from which participants left school ( $\leq 11,12$ and $>12$ ). Participants were also asked whether they had any physiciandiagnosed somatic health problems, such as diabetes, hypertension, coronary heart disease and cancer. Alcohol consumption (units per week), smoking habits (smoker, ex-smoker, never smoker) and marital status (married; divorced, separated, widowed; never married) were ascertained using standard questions. Of the 16349 veterans invited for interview, 15288 (94\%) actually participated.

In 1986, 6443 participants, selected at random, were invited to attend a thorough 3-day medical examination; 4462 (69\%) attended and full data, as indicated, were available for 4256. Mean age at medical examination was 38.3 years (range: 31.1-49.0). Height and weight were measured using standard protocols. $\mathrm{FEV}_{1}$ was determined by spirometry. Flow volume loops were recorded by a MedScience 570 Wedge Spirometer and a Digital DEC Writer 111 (St Louis, Missouri, USA) was used to transmit the analogue data from the spirometer to a pulmonary function computer. The spirometer was calibrated daily; at the beginning of each day, atmospheric pressure and temperature were entered into the computer. For quality control, on each day, one participant was randomly selected for repeat testing by a different examiner. Reproducibility was good and the coefficient of variation was $4.4 \%$

\section{Statistical analyses}

Analyses were undertaken using PASW Statistics, V.18, software. We tested multiple linear regression models, with lung function, that is, $\mathrm{FEV}_{1}$, as the dependent variable and cognitive ability, that is, IQ score, as the independent variable. First, we tested a hier- archical model that, at step 1, adjusted for only age and height. Age and height have routinely been shown to affect lung function. IQ was entered at step 2. Second, we tested a further model that, in addition to age and height, adjusted at step 1 for weight, smoking, alcohol consumption, place of service, ethnicity, marital status, household income in midlife, education grade achieved and chronic diseases (ie, physician-diagnosed diabetes, hypertension, coronary heart disease and cancer). These are all variables that could be potential confounders of any association between IQ and $\mathrm{FEV}_{1}$. IQ was again entered at step 2 in this model. The following association statistics are reported: $\beta$, the standardised regression coefficient; $\Delta \mathrm{R}^{2}$, the proportion of additional variance in $\mathrm{FEV}_{1}$ explained by IO. Associations were considered statistically significant if $p<0.05$. In order to explore the impact of using alternative computations of lung function, $\mathrm{FEV}_{1}$ was also characterised as $\mathrm{FEV}_{1} /$ height $^{2}$ and as a percentage of predicted $\mathrm{FEV}_{1}{ }^{31}$ using a standard algorithm involving age and height to calculate predicted $\mathrm{FEV}_{1}{ }^{32}$ Since smoking has such a profound effect on lung function, it was considered important to determine whether any association between IO and lung function was evident in non-smokers. Accordingly, the fully adjusted model above was rerun excluding smokers. ${ }^{16} 17$

\section{RESULTS}

The participant characteristics are presented in table 1 . In the linear regression model that adjusted only for age at the medical examination and height, IQ was positively associated with $\mathrm{FEV}_{1}$

Table 1 Characteristics of participants

\begin{tabular}{|c|c|c|}
\hline Variable & Mean & SD \\
\hline $\mathrm{FEV}_{1}$ in litres & 4.04 & 0.66 \\
\hline $\mathrm{FEV}_{1} \%$ of predicted $\mathrm{FEV}_{1}$ & 99.54 & 14.63 \\
\hline Height in metres & 1.78 & 0.07 \\
\hline Weight in kilograms & 82.50 & 13.55 \\
\hline Age at medical examination in years & 38.33 & 2.52 \\
\hline Units of alcohol per week (median and IQR) & 2.00 & 9.00 \\
\hline \multirow[t]{2}{*}{ Standardised IQ score from enlistment } & 101.37 & 15.19 \\
\hline & \multicolumn{2}{|r|}{ Per cent } \\
\hline \multicolumn{3}{|l|}{ Ethnicity } \\
\hline White & \multicolumn{2}{|r|}{82} \\
\hline Black & \multicolumn{2}{|r|}{12} \\
\hline Other & \multicolumn{2}{|r|}{6} \\
\hline \multicolumn{3}{|l|}{ Place of service } \\
\hline Vietnam & \multicolumn{2}{|r|}{55} \\
\hline Other overseas & \multicolumn{2}{|r|}{26} \\
\hline USA only & \multicolumn{2}{|r|}{19} \\
\hline \multicolumn{3}{|l|}{ Smoking status } \\
\hline Smoker & \multicolumn{2}{|r|}{46} \\
\hline Ex-smoker & \multicolumn{2}{|r|}{28} \\
\hline Non-smoker & \multicolumn{2}{|r|}{26} \\
\hline \multicolumn{3}{|l|}{ Education grade } \\
\hline$\leq 11$ & & 12 \\
\hline 12 & \multicolumn{2}{|r|}{37} \\
\hline$>12$ & \multicolumn{2}{|r|}{51} \\
\hline \multicolumn{3}{|l|}{ Household income midlife } \\
\hline$\leq \$ 20000$ & & 28 \\
\hline$\$ 20000-\$ 40000$ & \multicolumn{2}{|r|}{50} \\
\hline$>\$ 40000$ & \multicolumn{2}{|r|}{22} \\
\hline \multicolumn{3}{|l|}{ Marital status } \\
\hline Married & & 74 \\
\hline Divorced/separated/widowed & & 18 \\
\hline Never married & & 8 \\
\hline Physician-diagnosed chronic disease & & 13 \\
\hline
\end{tabular}




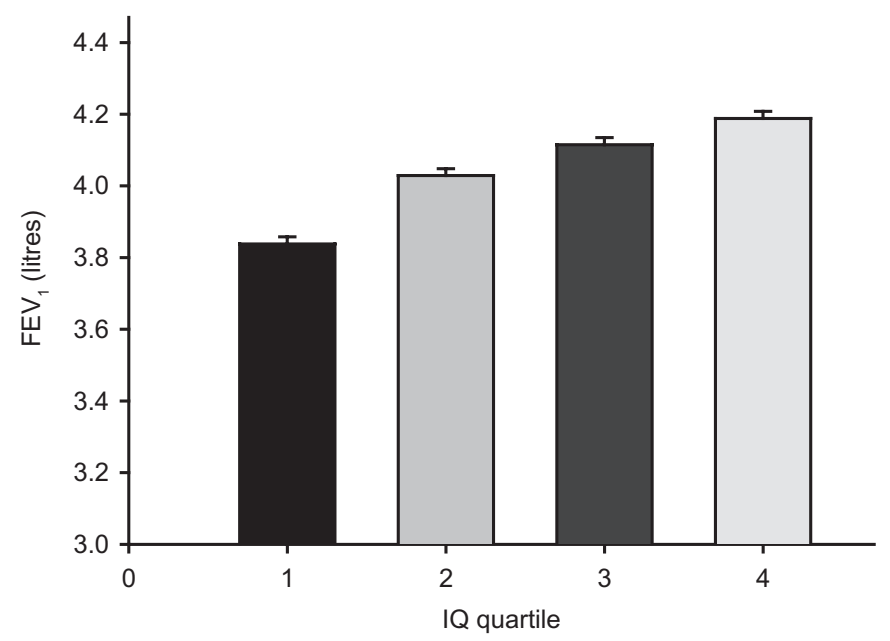

Figure 1 Mean $\mathrm{FEV}_{1}$ by quartile of IQ; the error bars are standard errors.

18 years later, $\beta=0.17, p<0.001, \Delta R^{2}=0.026$. A 1 -point reduction in IO was associated with a $7 \mathrm{ml}$ drop in $\mathrm{FEV}_{1}$. In addition, as would be expected, age at the medical examination was negatively associated and height positively associated with $\mathrm{FEV}_{1}$, $\mathrm{p}<0.001$. The association between IO and $\mathrm{FEV}_{1}$ is illustrated in figure 1 , which plots quartiles of $\mathrm{IQ}$ against $\mathrm{FEV}_{1}$; the $\mathrm{FEV}_{1}$ data are estimated means following adjustment for age and height. Inspection of figure 1 indicates a dose-response relationship between $\mathrm{IQ}$ and $\mathrm{FEV}_{1}$. In the regression model that additionally adjusted for all the other covariates, the association between IO and $\mathrm{FEV}_{1}$ was somewhat attenuated but remained statistically significant, $\beta=0.12, p=0.001, \Delta R^{2}=0.008$. In this case, a 1-point reduction in $\mathrm{IQ}$ was associated with a $5 \mathrm{ml}$ drop in $\mathrm{FEV}_{1}$. In addition to the association between age and height and $\mathrm{FEV}_{1}$, poorer lung function characterised those who smoked, consumed more alcohol, weighed more, were not white and had a diagnosed major disease. The full model is presented in table 2.

We again ran the fully adjusted models for the two other representations of lung function, $\mathrm{FEV}_{1} /$ height ${ }^{2}$ and $\mathrm{FEV}_{1} / \mathrm{FEV}_{1}$ predicted; for the former, we no longer adjusted for height and, for the latter, neither height nor age was entered. The outcomes were virtually identical to those reported above; IO was associated with $\mathrm{FEV}_{1} /$ height $^{2}, \beta=0.12, \mathrm{p}<0.001, \Delta \mathrm{R}^{2}=0.009$, and $\mathrm{FEV}_{1} / \mathrm{FEV}_{1}$ predicted, $\beta=0.12, \mathrm{p}<0.001, \Delta \mathrm{R}^{2}=0.009$. Current smoking had a substantial effect on $\mathrm{FEV}_{1}$; mean (SD) for never

Table 2 Predictors of lung function in the fully adjusted regression model

\begin{tabular}{lrrr}
\hline & $\boldsymbol{\beta}$ & $\mathbf{p}$ & $\Delta \mathbf{R}^{\mathbf{2}}$ \\
\hline Step 1 & & & \\
Height in metres & 0.40 & $<0.001$ & \\
Weight in kilograms & -0.03 & 0.035 & \\
Age at medical examination in years & -0.15 & $<0.001$ & \\
Units of alcohol per week & -0.03 & 0.015 & \\
Ethnicity & -0.09 & $<0.001$ & \\
Place of service & -0.02 & 0.123 & \\
Smoking status & -0.17 & $<0.001$ & \\
Education grade & -0.02 & 0.248 & \\
Household income midlife & 0.02 & 0.325 & \\
Marital status & 0.01 & 0.430 & \\
Physician-diagnosed chronic disease & -0.05 & $<0.001$ & 0.238 \\
Step 2 & & & \\
Standardised I0 score from enlistment & 0.12 & $<0.001$ & 0.008 \\
\hline
\end{tabular}

smokers, ex-smokers and current smokers was 4.15 (0.66), 4.14 $(0.65)$ and 3.92 (0.66). Analysis of variance, $F(2,4253)=66.52$, $\mathrm{p}<0.001$, indicated that the three smoking groups varied in lung function. Post hoc tests using the Newman-Keuls method indicated that the current smokers had poorer lung function than the ex- or never smokers ( $p<0.05$ in each case). Finally, the original $\mathrm{FEV}_{1}$ fully adjusted analysis was rerun excluding smokers. Again, the results were similar to those reported above, $\beta=0.13, p=0.001, \Delta R^{2}=0.010$.

\section{DISCUSSION}

Low cognitive ability in early adulthood was associated with poorer lung function in middle age in a large cohort of male Vietnam-era army veterans. As such, our results add weight to the findings of the two previous smaller scale studies that also show a positive association between cognitive ability and $\mathrm{FEV}_{1}{ }^{24}{ }^{25}$ In the present study, the relationship between low cognitive ability and poorer lung function remained statistically significant despite adjusting for a wide range of potential confounders, using alternative derivations of lung function, and when the analysis was restricted to participants who were not current smokers. This testifies to the robustness of the relationship.

As described, several studies have now shown that reduced lung function is related to future cognitive ability and cognitive decline. ${ }^{21-25}$ The present results, along with those from the two earlier reports, ${ }^{24} 25$ also indicate that low cognitive ability in youth increases the risk of reduced lung function later in life. Taken together, the evidence now suggests that cognitive ability and lung function have a bidirectional relationship. This is not without precedent. For example, there is evidence linking markers of inflammation, such as $C$ reactive protein, earlier in life with future cognitive decline. ${ }^{33} 34$ We have also recently shown in the present cohort that low cognitive ability was associated with a higher subsequent erythrocyte sedimentation rate, another marker of inflammation. ${ }^{8}$

The association between $\mathrm{FEV}_{1}$ and subsequent cognitive ability is generally explained in terms of processes such as inflammation, impaired fibrinolytic activity, oxidative stress and hypoxia associated with compromised respiratory function. ${ }^{35} 36$ Various pathways that might link low cognitive ability with subsequent adverse health outcomes, including impaired lung function, have been suggested. For example, a greater propensity for unhealthy behaviour, including smoking, alcohol consumption and poorer medical adherence and surveillance, among those with low cognitive ability has been cited. ${ }^{1}$ However, the present associations survived adjustment for both alcohol consumption and smoking, and the positive relationship between cognitive ability and future lung function was of the same order of magnitude in analyses restricted to non-smokers. Another possibility is that low cognitive ability might be a marker of poorer 'system integrity', such that various physiological systems mount less resistance to injurious environmental exposures across the life course. ${ }^{37}$ Finally, both poor lung function and low cognitive ability have also been regarded as markers of early life adversity including exposure to suboptimal nutrition, poverty, chronic childhood illness and psychosocial stress. ${ }^{16} 38$ Accordingly, it is possible that low cognitive ability and poor lung function are parallel products of shared antecedents, either genetic, epigenetic or early environmental. ${ }^{25} 39$ The present data set is insufficient to determine the relative merits of these various possibilities.

The present study is not without other limitations. First, only men were included and thus the issue of generalisation arises. 
However, there are no compelling reasons to believe that the present association was sex specific. The two previous studies demonstrating a relationship between cognitive ability and future lung function were conducted on mixed samples. ${ }^{24} 25$ Second, the effect sizes could be regarded as modest. Nevertheless, they are of the same order as those reported in the two previous studies. $^{2425}$ Third, without a measure of lung function in early adulthood, it is impossible to ascertain the direction of causality, as the association between cognitive ability and lung function could already have existed at the earlier age. Fourth, observational studies are prone to confounding by poorly measured or unmeasured variables. ${ }^{40}$ However, we adjusted for a more complete set of potentially relevant confounders than previous studies. Furthermore, in this context, our rather crude characterisation of smoking behaviour (smoker, ex-smoker, never smoker), rather than pack years, may have underestimated the effects of smoking on association between cognitive ability and lung function. Nevertheless, the association between cognitive ability and later lung function was of the same order in analyses restricted to non-smokers as it was in the whole sample. Finally, undoubtedly, the present study's greatest limitation is the absence of measures of environmental, including occupational, exposures to airborne toxins and pollutants. However, in this aspect our study is hardly unique; neither of the other two studies of cognitive ability and subsequent lung function were able to draw on such measures, ${ }^{24} 25$ which is perhaps testimony to the difficulty of collecting these sort of data. Nevertheless, it is quite conceivable that such environmental exposures were more common among those with poorer cognitive ability and, accordingly, mediated the relationship between cognitive ability and lung function. However, we would contend that income and education may be reasonable proxies for whether participants were more or less likely to be living in environments and working in occupations with such exposures; similarly, service in Vietnam could be considered a fair proxy for such exposures during military service. Our main finding withstands correction for income, education and place of service.

In conclusion, low cognitive ability in early adulthood was associated with reduced lung function, as indicated by lower $\mathrm{FEV}_{1}$, in middle age. This association was still evident following adjustment for a range of socio-demographic, anthropometric, lifestyle and health variables, and was evident with different representations of $\mathrm{FEV}_{1}$. Thus, it would appear that not only does lung function affect later cognitive ability, but also that poor cognitive ability earlier in life is associated with reduced lung function later in life.

Funding The Centre for Cognitive Ageing and Cognitive Epidemiology is supported by the Biotechnology and Biological Sciences Research Council, the Engineering and Physical Sciences Research Council, the Economic and Social Research Council, the MRC and the University of Edinburgh as part of the cross-council Lifelong Health and Wellbeing Initiative.

\section{Competing interests None.}

Ethics approval This study was approved by Centers for Disease Control.

Contributors DC conceived the idea; DC and ACP conducted analyses and drafted the manuscript with substantial input from IJD, LHM and GDB. The latter two provided the data set.

Provenance and peer review Not commissioned; externally peer reviewed.

\section{REFERENCES}

1. Batty GD, Deary IJ, Gottfredson LS. Premorbid (early life) IO and later mortality risk: systematic review. Ann Epidemiol 2007;17:278-88.

2. Batty GD, Wennerstad KM, Smith GD, et al. IO in early adulthood and mortality by middle age: cohort study of 1 million Swedish men. Epidemiology 2009;20:100-9
3. Chandola T, Deary IJ, Blane D, et al. Childhood IQ in relation to obesity and weight gain in adult life: the National Child Development (1958) Study. Int J Obes (Lond) 2006;30:1422-32.

4. Batty GD, Deary IJ, Schoon I, et al. Mental ability across childhood in relation to risk factors for premature mortality in adult life: the 1970 British Cohort Study. J Epidemiol Comm Health 2007;61:997-1003

5. Batty GD, Deary IJ, Macintyre S. Childhood IO in relation to risk factors for premature mortality in middle-aged persons: the Aberdeen Children of the 1950s study. J Epidemiol Comm Health 2007:61:241-7.

6. Lindgarde $\mathbf{F}$, Furu M, Ljung BO. A longitudinal study on the significance of environmental and individual factors associated with the development of essential hypertension. J Epidemiol Comm Health 1987:41:220-6.

7. Packard CJ, Bezlyak V, McLean JS, et al. Early life socioeconomic adversity is associated in adult life with chronic inflammation, carotid atherosclerosis, poorer lung function and decreased cognitive performance: a cross-sectional, population-based study. BMC Public Health 2011;11:42.

8. Phillips AC, Batty GD, van Zanten JJ, et al. Cognitive ability in early adulthood is associated with systemic inflammation in middle age: the Vietnam experience study. Brain Behav Immun 2011;25:298-301.

9. Gunnell D, Harrison G. Rasmussen F, et al. Associations between premorbid intellectual performance, early-life exposures and early-onset schizophrenia. Cohort study. Br J Psychiatry 2002:181:298-305

10. Batty GD, Deary IJ, Macintyre S. Childhood IO and life course socioeconomic position in relation to alcohol induced hangovers in adulthood: the Aberdeen children of the 1950s study. J Epidemiol Comm Health 2006:60:872-4.

11. Zammit S, Allebeck P, David AS, et al. A longitudinal study of premorbid IQ Score and risk of developing schizophrenia, bipolar disorder, severe depression, and othe nonaffective psychoses. Arch Gen Psychiatr 2004:61:354-60.

12. Batty GD, Mortensen EL, Osler M. Childhood IO in relation to later psychiatric disorder: evidence from a Danish birth cohort study. $\mathrm{Br} J$ Psychiatry 2005;187:180-1.

13. Clennell S, Kuh D, Guralnik JM, et al. Characterisation of smoking behaviour across the life course and its impact on decline in lung function and all-cause mortality: evidence from a British birth cohort. J Epidemiol Comm Health 2008;62:1051-6

14. Engstrom G, Hedblad B, Janzon L, et al. Respiratory decline in smokers and exsmokers-an independent risk factor for cardiovascular disease and death. J Cardiovasc Risk 2000;7:267-72.

15. Hole DJ, Watt GC, Davey-Smith G, et al. Impaired lung function and mortality risk in men and women: findings from the Renfrew and Paisley prospective population study. BMJ 1996;313:711-15; discussion 5-6.

16. Batty GD, Gunnell D, Langenberg C, et al. Adult height and lung function as markers of life course exposures: associations with risk factors and cause-specific mortality. Eur J Epidemiol 2006:21:795-801.

17. Strachan DP. Ventilatory function, height, and mortality among lifelong nonsmokers. J Epidemiol Comm Health 1992;46:66-70.

18. Cook NR, Evans DA, Scherr PA, et al. Peak expiratory flow rate in an elderly population. Am J Epidemiol 1989;130:66-78.

19. Emery CF. Cognitive functioning among patients in cardiopulmonary rehabilitation J Cardiopulm Rehabil 1997:17:407-10.

20. Cerhan JR, Folsom AR, Mortimer JA, et al. Correlates of cognitive function in middle-aged adults. Atherosclerosis Risk in Communities (ARIC) Study Investigators Gerontology 1998:44:95-105.

21. Albert MS, Jones K, Savage CR, et al. Predictors of cognitive change in older persons: MacArthur studies of successful aging. Psychol Aging 1995;10: 578-89.

22. Chyou PH, White LR, Yano K, et al. Pulmonary function measures as predictors and correlates of cognitive functioning in later life. Am J Epidemiol 1996:143:750-6.

23. Emery CF, Pedersen NL, Svartengren M, et al. Longitudinal and genetic effects in the relationship between pulmonary function and cognitive performance. J Gerontol $B$ Psychol Sci Soc Sci 1998;53:P311-17.

24. Richards $\mathbf{M}$, Strachan D, Hardy R, et al. Lung function and cognitive ability in a longitudinal birth cohort study. Psychosom Med 2005;67:602-8.

25. Deary IJ, Whalley LJ, Batty GD, et al. Physical fitness and lifetime cognitive change. Neurology 2006;67:1195-200.

26. Batty GD, Gale CR, Mortensen LH, et al. Pre-morbid intelligence, the metabolic syndrome and mortality: the Vietnam Experience Study. Diabetologia 2008:51:436-43

27. Phillips AC, Batty GD, Gale CR, et al. Generalised anxiety disorder, major depressive disorder, and their comorbidity as predictors of all-cause and cardiovascular mortality: the Vietnam Experience Study. Psychosom Med 2009;71:395-403.

28. Montague EK, Williams HL, Lubin A, et al. Army tests for assessment of intellectua deficit. U S Armed Forces Med J 1957;8:883-92.

29. Weiss A, Gale CR, Batty GD, et al. Emotionally stable, intelligent men live longer: the Vietnam experience study cohort. Psychosom Med 2009;71:385-94.

30. Batty GD, Shipley MJ, Mortensen LH, et al. IO in late adolescence/early adulthood risk factors in middle age and later all-cause mortality in men: The Vietnam Experience Study. J Epidemiol Community Health 2008;62:522-31.

31. Miller MR, Pedersen OF, Dirksen A. A new staging strategy for chronic obstructive pulmonary disease. Int J Chron Obstruct Pulmon Dis 2007:2:657-63.

32. Quanjer PH, Tammeling GJ, Cotes JE, et al. Lung volumes and forced ventilatory flows. Report Working Party Standardization of Lung Function Tests, European 
Community for Steel and Coal. Official Statement of the European Respiratory Society. Eur Respir J Suppl 1993;16:5-40.

33. Laurin D, David Curb J, Masaki KH, et al. Midlife C-reactive protein and risk of cognitive decline: a 31-year follow-up. Neurobiol Aging 2009;30:1724-7.

34. Rafnsson SB, Deary IJ, Smith FB, et al. Cardiovascular diseases and decline in cognitive function in an elderly community population: the Edinburgh Artery Study. Psychosom Med 2007:69:425-34.

35. Liao D, Higgins $\mathrm{M}$, Bryan NR, et al. Lower pulmonary function and cerebral subclinical abnormalities detected by MRI: the Atherosclerosis Risk in Communities study. Chest 1999;116:150-6.
36. Gibson GE, Pulsinelli W, Blass JP, et al. Brain dysfunction in mild to moderate hypoxia. Am J Med 1981;70:1247-54.

37. Deary IJ, Der G. Reaction time explains IQ's association with death. Psychol Sci 2005:16:64-9.

38. Kilgour AH, Starr JM, Whalley LJ. Associations between childhood intelligence (I0) adult morbidity and mortality. Maturitas 2010;65:98-105.

39. Barker D. Fetal Origins of Adult Disease London: British Medical Association, 1992.

40. Christenfeld NJ, Sloan RP, Carroll D, et al. Risk factors, confounding, and the illusion of statistical control. Psychosom Med 2004;66:868-75.

Advancing Postgraduates. Enhancing Healthcare.

The Postgraduate Medical Journal is dedicated to advancing the understanding of postgraduate medical education and training.

- Acquire the necessary skills to deliver the highest possible standards of patient care

- Develop suitable training programmes for your trainees

- Maintain high standards after training ends

Published on behalf of the fellowship for Postgraduate Medicine

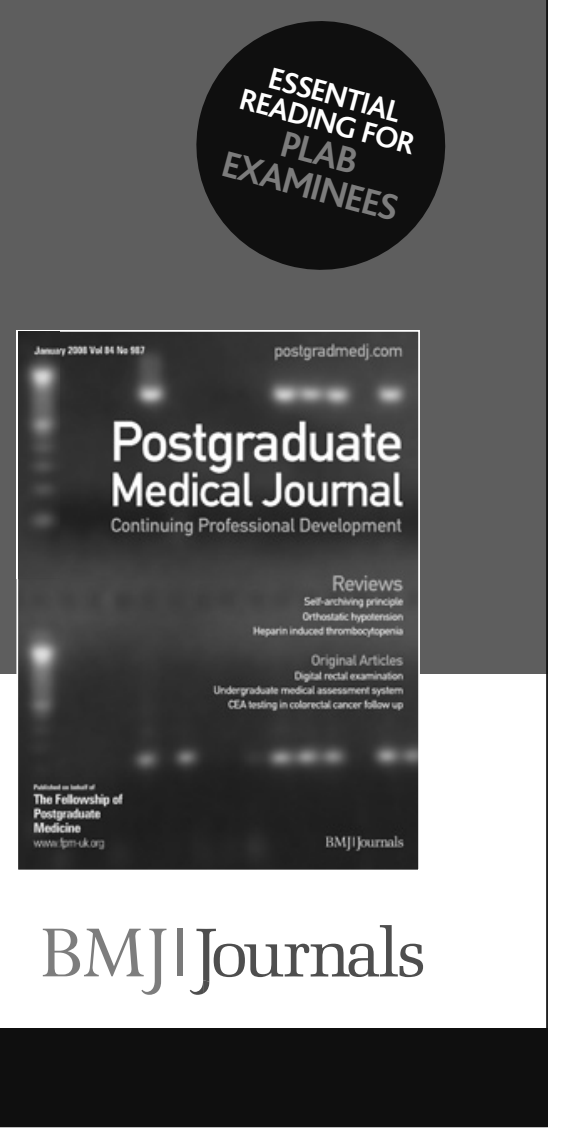

FOR MORE DETAILS OR TO SUBSCRIBE, VISIT THE WEBSITE TODAY

BMJIJournals postgradmedj.com 